Robson suggests, that the present somewhat lamentable state of affairs has arisen.

On the other hand, it may be asked what have political scientists done to establish themselves in the influential position which Prof. Robson has marked out for them. Is theirs, in fact, a "master science'? Here Prof. Robson injects into the discussion some very wise remarks, which place the problem of the under-development of political science in a somewhat different setting. It is evident to him that, in the light of our present knowledge, it is beyond the power of political science "to formulate general laws which associate in a precise manner particular eauses with specified effects". The political scientist is, indeed, "dealing with a realm of thought and action about which men and women hold the most profound differences of opinion and belief". His methods are imprecise, and his work is apt to be influenced too directly by the winds of passion. If this is accepted as the truth, where, it must be asked, do political scientists stand in relation to the other social and natural sciences ?

The bold claim that political science can exist as a 'master science' must indeed be relinquished in favour of something more humble. The solving of such problems as the 'cold war', the international control of atomic energy, race relations in Africa, the stimulation of "genuine citizen participation in government", and the protection of the world against "stiff-necked bureaucracies incompatible with democracy", which Prof. Robson regards as the concern of the political scientist, is a task that will require the collaboration of all social scientistssupposing that they do not prove to be too much for the wit of man altogether. If political science is to flourish it must, in present circumstances, accept more help from the other social sciences than it contributes to them.

We thus find ourselves in the position of seeking the foundations of a political science that can be taught as part of a liberal education. It may be suggested that it is because this has not been done with sufficient intellectual courage that the subject has failed to expand with the rapidity that the necessities of our times would appear to demand. The solving of the political problems that are so essentially bound up with the acquisition and exercise of power within any society can only be achieved on an empirical basis; it is only in this way that we shall be able to lay the foundations of a subject of study which can be called truly scientific.

In Great Britain we are in an especially favourable position to attempt this, because our tradition in political science has always been empirical or practical as well as philosophical or theoretical. We have never taken a sentimental or idealized view of the personalities or behaviour of our rulers. As William Pitt remarked at the end of the eighteenth century, "unlimited power is apt to corrupt the minds of those who possess it", and we have acted accordingly. It was in Prof. Robson's own London School of Economies that Graham Wallas made such strenuous efforts to apply practical wisdom of this kind to the conditions of his own day, and it is for the contemporary political scientist, in collaboration with sociologists, anthropologists and psychologists, to work out a theory dealing with the use of political power which can be applied both to problems of government and administration, on one hand, and to those of the individual politician, administrator and citizen on the other.

T. S. SrmeY

\section{EFFECTS OF RADIATION AND OTHER DELETERIOUS AGENTS ON EMBRYONIC DEVELOPMENT}

$\mathrm{T}$

HE Biology Division of the United States Atomic Energy Commission sponsored a symposium on the effects of radiation and other deleterious agents on embryonic development, which was held on April 20, 1953, at the Oak Ridge National Laboratory, Tennessee. The proceedings have been published as a supplement to the Journal of Cellular and Comparative Physiology (43, Supp. 1, May 1954. Pp. $337+6$ plates; from the Wistar Institute of Anatomy and Biology, Philadelphia; n.p.). This symposium volume contains eleven full-length papers and some short but valuable summarizing remarks by Dr. Paul Weiss. Each of the papers is followed by a discussion by the author and members of an obviously interested and critical audience.

Four of the papers deal with the effects of ionizing radiations on developing embryos of the rat, an amphibian and the mouse; and one may perhaps add to this group a study on the outcome of pregnancy in women exposed to the atomic bomb blast in Nagasaki. Experimental papers in this group have been mainly concerned to plot out the different types of radiation damage which follow exposure to irradiation at different times of embryonic development. The facts which are revealed are interesting and probably of considerable technological importance in a world in which ionizing radiation seems likely to become one of the normal hazards not only of war but also of peaceful industry. The interpretation which should be put on them still remains rather obscure. Much of the discussion is in terms of critical periods ; but, as Weiss points out, one is not justified in assuming that the crucial activities which bring about the final visible effects are produced at the actual time at which the irradiation is given, a situation which makes the identification of the critical periods by no means easy. Moreover, the evidence suggests that radiation may produce many different types of damage, not only on the chromosomes but also on the cytoplasm.

One might hope, perhaps, to have rather more understanding of the kind of damage produced by certain chemical substances such as the nitrogen mustards, the vitamins, cortisone, etc. There are five papers dealing with such topics. Again, the reader is confronted with a large amount of actual information, the explanation of which remains for the most part still to seek. Perhaps the most interesting of this group of papers is a further report by Landauer of the recent progress of his massive and thorough study of the production of phenocopies by chemical means in chick embryos. In general, however, one gets the impression that our understanding of embryonic development would be better advanced by studies which employ agents the activities of which are more precisely understood than those of irradiation or toxic substances such as the mustards (for example, specific enzyme poisons or metabolic analogues); while for the interpretation of the embryonic effects of these 'blunderbuss' deleterious agents one will probably have to wait until studies on simpler systems have revealed more precisely the nature of the effects which they produce. 